\title{
Design of Automatic Control System for Boiler
}

\author{
Xinya Chen \\ Department of Mechanical and Electrical Engineering \\ Henan Mechanical \& Electrical Engin. College \\ Xinxiang, China \\ e-mail: xinyachen@163.com
}

\author{
Zhen Chen* \\ Department of Electronic and Communication \\ Engineering \\ Henan Mechanical \& Electrical Engin. College \\ Xinxiang, China \\ e-mail: chenzhen22@163.com \\ * Corresponding Author
}

\begin{abstract}
The boiler control system studied in this paper applies advanced PLC, digital adjusting instrument and imported full-automatic combustion process controller, and it is designed to an advanced full-automatic control system of boiler by combing PLC (programmable) technique, technique of digital adjusting instrument and computer and communications technology. Furthermore, it can be connected to industrial control computer to constitute DCS system. This system is a control system specifically developed for the operating characteristics of gas(oil)-fired boiler based on Siemens S7 PLC, which has the excellent quality of industrial control products of Siemens $S 7$ series in the aspect of hardware, and applies the control algorithm of thermal control theory of boiler and the thermal control experience of the boil manufacturer in charge of system design and operation adjustment in the aspect of software, to make the automatic input rate of full load of the boiler realize $100 \%$ full-automatic control.
\end{abstract}

Keywords-boiler; automatic control system; full-automatic PID; three-impulse cascade control system; furnace negative pressure

\section{INTRODUCTION}

The entire control system consists of host computer operating station, Siemens S7-200 controller[1], LANDIS \& GRY controller of dedicated combustion process, touch screen (POD) and digital adjusting instrument, communication network, on-site primary instrumentation and actuator, and its functions include DAS, CSC, MCS and other auxiliary control.

All system detecting points and associated configuration screen can achieve display, alarming, data management and interrupt operation on the touch screen[2] (POD) and digital adjusting instrument. Since the hardware configuration is classic and Siemens product itself is qualified with openness, global supply and other characteristics[3], this system is a gas(oil)-fired industrial boiler control system qualified with good maintaining and protecting performance, high timeliness, excellent stability, strong anti-interference ability and friendly humancomputer interface.

\section{OVERALl GOALS OF DESIGN}

To meet the requirements of remote and centralized control[4]; first-rate operation level of boiler automation, and wide automatic adjusting capability of load; beautiful monitoring screen, simple to apply, easy to learn, and easy to operate; fast data processing speed, and high timeliness; to improve the work efficiency of operating personnel, and to meet the requirement of all-around operators of boiler[5]; to meet users' future functional requirement of expanding the system to DCS.

\section{SySTEM DESIGN}

\section{A. Overview of System Design}

The control system is designed in accordance with the thermal control requirements of gas(oil) boiler, and host computer operating station is responsible for the centralized monitoring and control of all process conditions as well as the analysis and recording of all status and trends of process parameters; in addition, the upper main control unit, Siemens S7 control unit, and digital adjusting instrument control the operation of boiler; the application of double layer can achieve the goal of stable and reliable operation of production process equipment[6].

Large DCS system of factory management level can directly connect with on-site computer operating station with Ethernet port of RJ45 standard, and TCP / IP protocol achieves the purpose of data sharing and interactive operation by establishing client / server access mechanism.

Signal collected on site and system control output are connected to primary instrument or actuator (electric control valve) in I / O module of the control unit by the signal cable, and the display instrument is set on the key parameter operating platform at the same time. Primary instrument, cable, electric control valve, actuator and other components are all approved products, and their performances are guaranteed by the selected brands[7].

\section{B. Main Functions of System Design and the Implementation}

The automation degree and the ability to deal with incidents (alarms, analysis, guidance, treatment, etc.) after the completion of the entire control system are designed on the basis of increasing efficiency and reducing energy consumption at the greatest extent. It is controlled as a whole object, and the automation process in accordance of technological process is completed by system coordination, to achieve energy balance; to safeguard the safe, reliable and efficient operation of boiler and auxiliary equipment and the start and stop[8]. To improve the technical and economic benefits of system operation: boiler and auxiliary equipment operate on the upper limit of the nominal parameter, making boiler and auxiliary equipment be in the optimum operating condition; realizing automation investment, improving reliability, reducing misoperation and reducing the accident rate. 
The main techniques applied by analog control are combustion control (main steam pressure control), threeimpulse control of boiler water level and negative pressure control of furnace[9]. The boiler is a complex thermal control object of tight coupling of technological parameters with multivariable input and output. The control effect of system is mainly reflected in control system's processing mode of various analog quantities (ie, usually mentioned MCS system). The most cutting-edge technology and the most sophisticated instruments of modern thermal control are applied in almost all aspects from the collection of each analog quantity to the control output of adjusting parameters, and numerous operating experience in the field is also applied.

The time constant of boiler is small, control parameter coupling is serious, and that conducting decoupling to achieve the control difficulties of classic PID regulation is difficult[10], so we use the control method combining selfadaptive load segment control, parameter range setting and PID regulation, to maximize the data computing power of computer.

\section{1) Vapor pressure - combustion adjustment}

The basic task of the automatic adjustment of boiler combustion system is to make the heat generated by fuel combustion adapt to the need of steam load, as well as to maintain the economical combustion and safe operation of boiler.

The block diagram of its control principle is shown as follows:

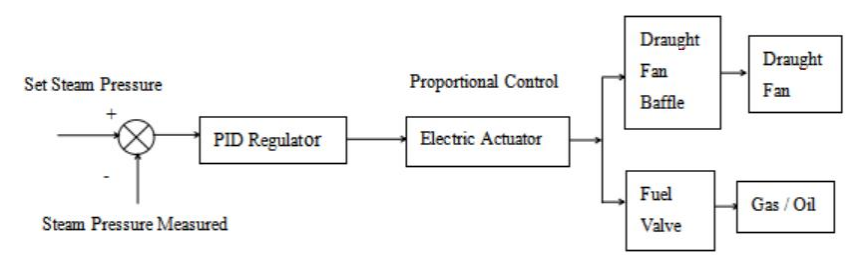

Figure 1.Schematic diagram of automatic PID combustion control of steam boiler

\section{2) Three-impulse Control of Boiler Water Level}

The stability of boiler water level influences various aspects of boiler including safety, efficiency and economy, so it is necessary to take effective measures to control the stability of boiler water level. The automatic adjustment task of boiler feedwater is to make feedwater quantity track the evaporation capacity of boiler and make boiler water level be within the range allowed by process.

Liquid level control has following three types: single-impulse control, a single-parameter and singlecircuit control system that applies water level as the only adjustment signal; double-impulse control, a dualparameter control system that uses steam flow as supplementary signal; three-impulse control, a threeparameter control system that uses feedwater flow and main steam flow as supplementary signals. And threeimpulse regulating system can further be divided into three-impulse single-stage control and three-impulse cascade control.

The complexity degrees of the three control algorithms are different, and their control effects are also quite different, for example, the control effect of single- impulse is the poorest and that of three-impulse is the best under the condition that the control parameter settings are in the optimal state. Three-impulse control of boiler water level is also known as feedwater control, reflecting the dynamic equilibrium between feedwater amount and steam supply, and is a typical cascade and feedforward control method. Feedwater flow is applied as secondary circuit, to overcome the disturbance of feedwater flow change; boiler water level is used as main circuit; steam flow is applied as feedforward quantity, to overcome false water level phenomenon, to achieve high control accuracy of water level. The system applies cascade and feedforward three-impulse control algorithm, and the error of steady state is controlled as $\leqslant \pm 5 \mathrm{~mm}$ under normal circumstances.

The block diagram of the control principle of threeimpulse cascade control system is shown as follows:

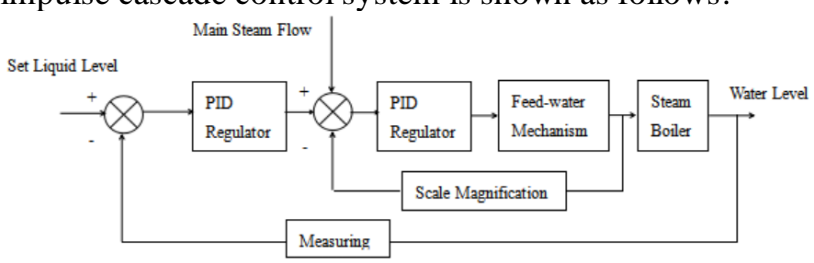

Figure 2. The block diagram of the control principle of three-impulse cascade control system

\section{3) Negative Pressure Control of Furnace}

To reduce heat loss, improve combustion economy, and strengthen operational safety, it is necessary to control the negative pressure of boiler furnace within a very stable range. In air-induced control program, the negative pressure measured value and the set value of furnace are calculated together in PID regulating loop, and the operating results control the operation of air-induced transducer and meet the operating requirements of the boiler. Since the change of total wind quantity can only be reflected on the measured value of negative pressure after a while, the total wind quantity is directly brought into the loop as the feedforward signal in air-induced control program, to make the system response quickly to the change of the total wind quantity.

Negative pressure of furnace reflects the equilibrium relationship between output air and induced air, and the goal is to ensure that boiler always maintains a stable state of negative pressure during the operational process, in order to ensure its safe and efficient operation. Its block diagram of control principle is shown as follows:

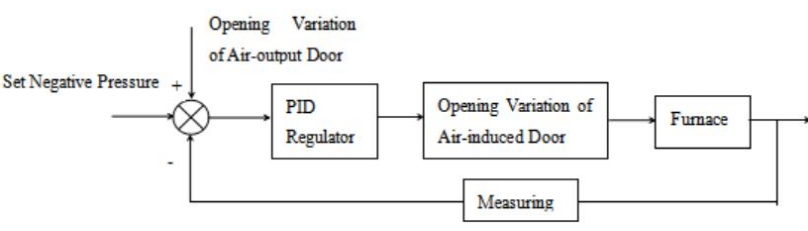

Figure 3.The block diagram of the control principle of furnace negative pressure

\section{DIGITAL CONTROL}

For most industrial objects, it has a large lag, so that the performance of the control system is decreased, the stability is reduced, and the transition process is worse. For time longer system, people are more interested in the 
requirements of the system is not overshoot or very little overshoot, and adjust the time is allowed to end in a more sampling period, therefore stability and no overshoot are the main design indicators. Dalin algorithm is an algorithm for this kind of system, the design goal of Dalin algorithm is to design a suitable digital controller, so that the whole closed-loop system expected to transfer function is equivalent to a pure lag of the first order inertial link, from the system does not generate overshoot, while ensuring the stability of the system. Dalin algorithm requires the use of a continuous first order inertial link in the choice of the pulse transfer function to replace the least beat polynomial.

\section{A. Model building}

The transfer function of the generalized controlled object is $W_{d}(s)=\frac{10 e^{-s}}{(s+1) s}$, Sampling period is $\mathrm{T}=0.5 \mathrm{~s}, T_{1}=1, K=1, N=\tau / T=2$. The function of the System generalized controlled object is

$$
D(\mathrm{z})=\frac{\mathrm{z}^{-N-1}\left(1-\mathrm{e}^{\frac{-\mathrm{T}}{\mathrm{T}_{0}}}\right)}{1-\mathrm{e}^{\frac{-\mathrm{T}}{\mathrm{T}_{0}}} \mathrm{z}^{-1}-\left(1-e^{\frac{-T}{T_{0}}}\right) z^{-N-1}} \cdot \frac{1}{G(z)}=\frac{2.524\left(1-0.6065 z^{-2}\right)}{\left(1-z^{-1}\right)\left(1+0.90933 z^{-1}+0.9933 z^{-2}\right)}
$$

From the above formula, $\mathrm{D}(\mathrm{z})$ has three poles, $z_{1}=1, z_{2}=-0.4967+0.864 j, z_{3}=-0.4967-0.864 j$.

$\mathrm{Z}=1$ at the poles will not cause the ringing phenomenon caused by the pole is ringing :

$$
\left|z_{2}\right|=\left|z_{3}\right|=\sqrt{1-\mathrm{e}^{\frac{-\mathrm{T}}{\mathrm{T}_{0}}}}=0.9966=1
$$

$\mathrm{Z}=1$, plug type can eliminate the ringing phenomenon , at this time $D(z)=\frac{0.8451\left(1-0.6065 z^{-1}\right)}{1-z^{-1}}$.

\section{B. Structure diagram of control system}

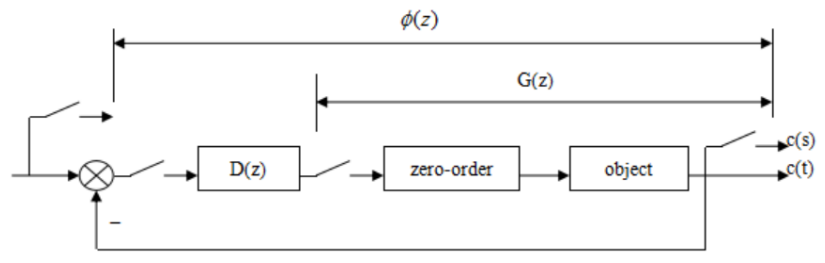

Figure 4. Structure diagram of control system

\section{SIMULINK Simulation}

According to the design steps of Dalin algorithm, the digital controller $\mathrm{D}(\mathrm{z})$ is designed, which is applied to the design of digital controller in Figure 5.

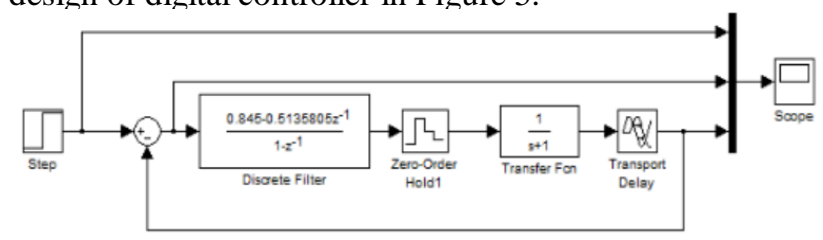

Figure 5. Simulink block diagram of Dalin algorithm control system

$$
G(s)=\frac{1-e^{-T S}}{s} W_{\mathrm{d}}(\mathrm{s})=\frac{\left(1-e^{-0.5 s}\right)}{s(s+1)}
$$

The impulse transfer function of the generalized object can be obtained:The impulse transfer function of the generalized object can be obtained:

$$
G(\mathrm{z})=K z^{-N-1} \frac{1-e^{\frac{-T}{T_{1}}}}{1-e^{\frac{-T}{T_{1}}} z^{-1}}=\frac{0.3935 z^{-3}}{1-0.6065 z^{-1}}
$$

According to the Dalin algorithm is the design of a digital controller, so that the whole closed-loop system of the pulse transfer function is equivalent to a pure lag of an inertial link, set $\mathrm{T} 0=0.1 \mathrm{~s}$ :According to the Dalin algorithm is the design of a digital controller, so that the whole closed-loop system of the pulse transfer function is equivalent to a pure lag of an inertial link, set $\mathrm{T} 0=0.1 \mathrm{~s}$ :

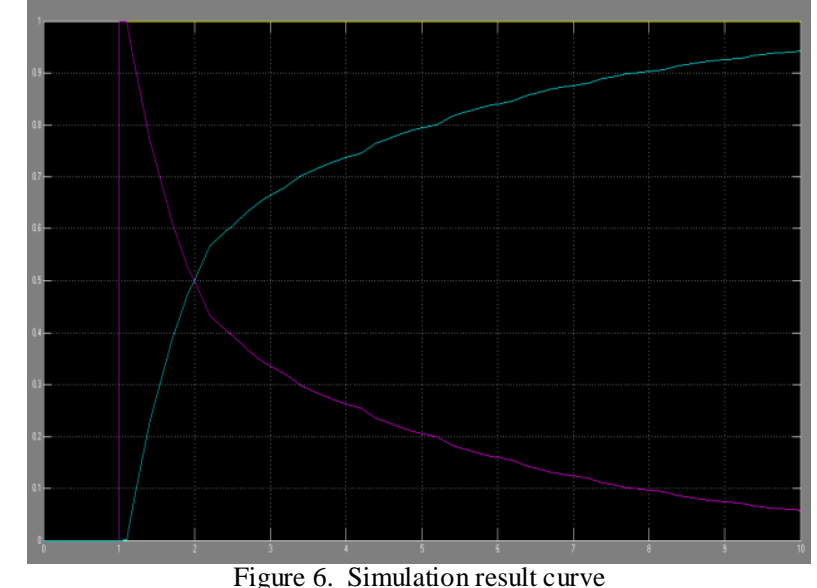

\section{DESIGN OF LIQUID LEVEL SENSOR}

The liquid level sensor is mainly composed of a high brightness diode and a light sensitive transistor. Water level detection is by four pairs of bright diode and the photosensitive triode tube are respectively arranged in four different locations, top-down four output ports are respectively connected with the MCU P1.0 and P1.1, P1.2, p1.3 ports, real-time detection of the water level in the boiler. When the water level reaches the position of a light sensitive transistor, the output port of the single chip output is high; when the water level is lower than the position of the photosensitive transistor, the output port of the output port is low. The first position from top to bottom level limit alarm line, when the water level is higher than the position, the control system will automatically alarm real boiling water, to the attention of staff, water solenoid valve may fail; the second position is the automatic stop line, namely when the water level higher than the position, the control system will automatically shut off the water solenoid the water stop 
valve; third position automatic line, namely when the water level is lower than this, the control system will automatically turn on the water valve, water boiling water; the fourth position is the water level alarm line, when the water level is lower than the position, will the real control system of boiling water automatic alarm, to remind the attention of the staff. Water solenoid valve to be out of order.

The photosensitive three stage tube is a kind of analog photoelectric sensor. The height of the liquid level is measured by absorbing the light of the bright diode, and the conversion of the light current to the analog sensor ADC0809. The working principle of the photoelectric sensor is based on the different forms of the photoelectric effect.The sensitive range of photoelectric sensor is much more than the sensitive range of inductance, capacitance, magnetic force and ultrasonic sensor. In addition, the size of the photoelectric sensor is very small, and the sensitive range is very wide, coupled with the housing has a lot of styles, can be used almost everywhere. Finally, with the continuous development of technology, photoelectric sensor in terms of price can be the same as other technology manufacturing sensor competition.

\section{CONCLUSIONS}

This design can directly observe the change of boiler pressure, temperature and various other I/O and analog quantities on industrial personal computer (IPC) and touch screen (POD), and also can observe the combustion state on IPC. When the steam pressure, water level and temperature of boiler become abnormal, the output locks the control system, resulting in audible and visible alarm and a hint for boiler operators to remove faults as required. Controls parameters are set freely on the IPC or touch screen. It has history recording function of important data, and can help operators to analyze boiler running condition, display faults on the window and provide online help. And it provides Chinese information tips, so ordinary operator can independently operate system equipment.

\section{REFERENCES}

[1] J Wang,C Ji,L Cao and Q Jin., "Design and realization of automatic control system for boiler based on model free adaptive control," 2th Annual Conf. Control \& Decision Japan, p. 1881 1886, 2011.

[2] CF Wang,YB Qiu, "The automatic control system of circulatory fluidized-bed boiler based on programmable control technology," Manufacturing Automation,vol.18,pp.34-43,April ,2014.

[3] Y Ding, "Design and Application of DCS Automatic Control System in Song Yuli Boiler Room Project.”, Electrical Technology of Intelligent Buildings,vol.23, pp.68-73,October,2013.

[4] W Lin, "Design of automatic control system for marine exhaust boiler," Marine Electric \& Electronic Engineering, vol.53,pp. 113122,May,2014.

[5] BU Ying yong,YAO Xiu chao, "Design of Boiler Deashing Device Automatic Control System on PLC," Instrument Technique \& Sensor,vol.67, pp.39-47,June,2013.

[6] X Li, "The design of Industrial Coal-burning Boiler automatic Control System," IEEE Transl. J. Magn, vol. 2, pp. 740-741, August ,2015.

[7] CY Lai, "Design and Application of the Automatic Control System for Boiler Feeding Water Using Frequency Conversion Method," Applied Energy Technology, vol. 37, pp. 40-51, 2011.

[8] YU Jing, "Design of Automatic Control System of Centralized Heat Supply in Gas-fired Boiler," World Sci-Tech R \& D, vol. 12, pp. 99-107, 2012.

[9] G Xin, "Modular Design of Automatic Control System for Boiler Converted from Coal to Natural Gas,"'Gas \& Heat,vol. 6, pp.30-41, 2012.

[10] ZJ Wang, J Hao, "Automatic control system design for the boiler combustion process based-on S7-200PLC," Light Metals, vol. 42, pp. 57-64,Dec. 2014. 